\title{
OBSERVATIONS ON THE ELECTROENCEPHALOGRAPH DURING EXPERIMENTAL AND CLINICAL CARDIO-PULMONARY BY-PASS
}

\author{
BY \\ P. ClifFE, CHARLES DREW, GERALD KEEN, AND D. B. BENAZON \\ From Westminster Hospital, London
}

(RECEIVED FOR PUBLICATION JANUARY 6,1959 )

An essential feature of cardio-pulmonary by-pass is the provision of adequate cerebral perfusion during open heart surgery.

Although various methods exist for measuring cerebral blood flow, they involve the exposure and possible transection of major cerebral vascular channels and are therefore limited to the experimental field. An indirect method of assessing cerebral blood flow is necessary when by-pass procedures are undertaken in human surgery. The observations in this paper are based on more than 100 continuous electroencephalographic tracings during cardio-pulmonary by-pass, most of which were obtained in the experimental laboratory. During this experience we encountered many pitfalls associated with this type of surgery and these are reflected in alteration of the E.E.G. pattern.

Experiments without the use of cardiopulmonary by-pass have also been devised in order to amplify knowledge derived from the routine observations.

\section{METHOD}

The perfusion apparatus employed was the LilleheiDeWall bubble oxygenator with "sigmamotor" pumps, and its use has been described (DeWall, Warden, Read, Gott, Ziegler, Varco, and Lillehei, 1956 ; Drew, Cliffe, Scurr, Forrest, Pearce, King, Coles, Leveaux, and Zilva, 1957).

The Ediswan portable electroencephalographic equipment has been used throughout. The head is shaved unilaterally and the skin is cleaned with ether. Silver electrodes coated with electrode jelly are applied to the clean, dry skin and secured with adhesive strapping. This is sprayed with "nobecutaine," which prevents drying out at the site of application.

The two active electrodes are placed on the supra-orbital ridge and the occiput and the neutral electrode is attached to the inner surface of the homolateral ear.
Interference from a 50-cycle electrical supply is avoided by discarding the mains earth and arranging to connect the neutral electrode and the earth return of all other electrical apparatus to a separate common earth by connexion to a water tap. This eliminates the presence of earth loops.

Another common source of interference is due to a high skin resistance at the electrodes. The electrodes properly applied ensure that this is less than 2,000 ohms at each lead and such values are maintained for several hours.

\section{RESUlTS}

The E.E.G. tracings that are reproduced and discussed were obtained under the following conditions :

1. (a) Normal anaesthesia, (b) anaesthesia with cerebral arterial occlusion, (c) perfusion with desaturated blood; (2) normal perfusion with cardio-pulmonary by-pass ; (3) hypotension due to $(a)$ poor perfusion, $(b)$ obstructed venous return, (c) protamine shock, (d) inadequate cardiac massage ; (4) varied site of perfusion, (a) brachial artery, (b) carotid artery; (5) thoracic inlet obstruction ; and (6) superior vena caval occlusion.

Normal E.E.G. UNDER ANAESTHESIA. Anaesthesia was induced with a sleep dose of thiopentone and succinylcholine, $1 \mathrm{mg}$. per $\mathrm{kg}$. body weight, and maintained with nitrous oxide and oxygen.

In the dog under these conditions the electrical discharge from the cortex has a principal frequency band of 8 to 14 cycles per second with an amplitude of 30 to 65 microvolts and such a trace is shown in Fig. 1. The arterial blood pressure recorded by an intra-aortic catheter was $170 / 110 \mathrm{~mm} . \mathrm{Hg}$ and the E.C.G. showed normal complexes.

ANaesthesia with Induced Cerebral Anoxia. -An experiment was designed to demonstrate the effect on the E.E.G. of cerebral anoxia. A dog 


\section{B.B.G.}

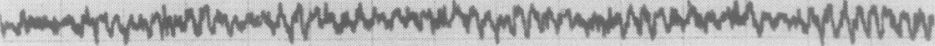

NORizą E.B.Q. PRTOR TỎ BYPAS\&

200

roo WWWWWWWWWWWWWWh

B.P.

s.c.0.

FIo. 1

Before Clamping Vessels

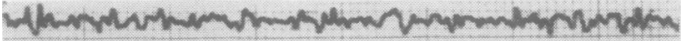

Clamped One Minute

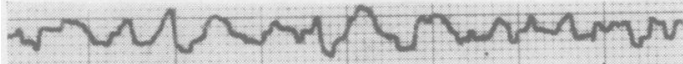

Clamped Three Minutes

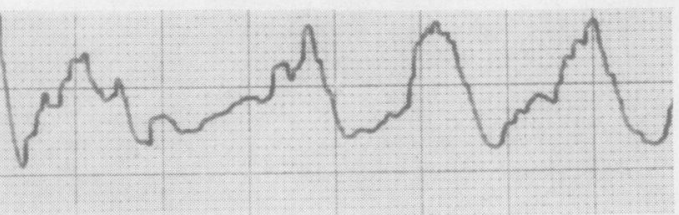

Clamped Four Minutes

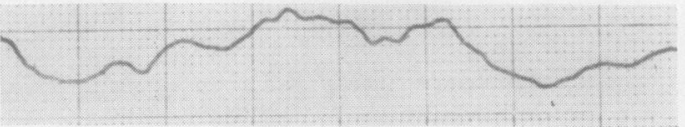

Clamped Fifteen Minutes

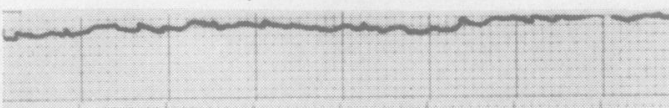

Clamp Off Five Minutes

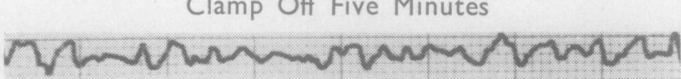

Clamp Off Fifteen Minutes

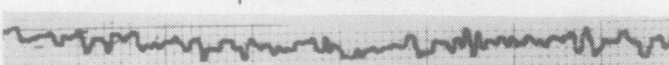

Fig. 2a

\section{Before Perfusion.}

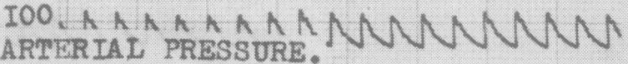
0 E.c.g. Whandandadahana

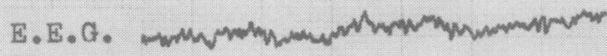

Venous Pressure

Arterial Oxygen, $94 \%$
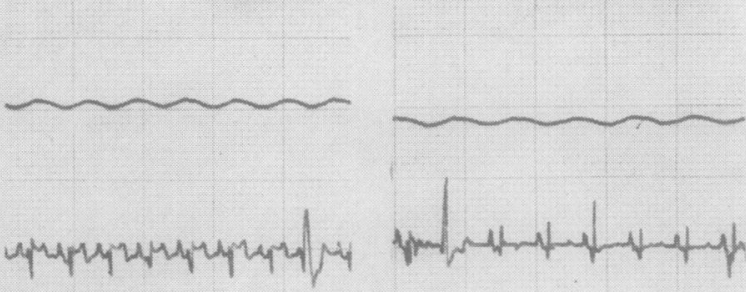

Arterlal Oxygen, $62 \%$

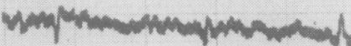

Arterlal Oxygen, $96 \%$ 


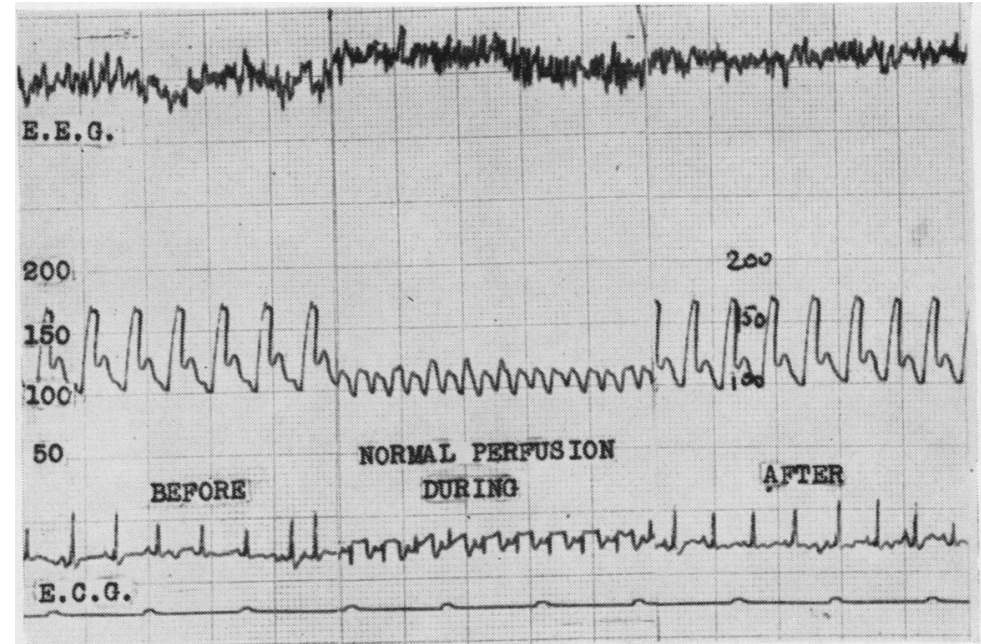

Fig. 3

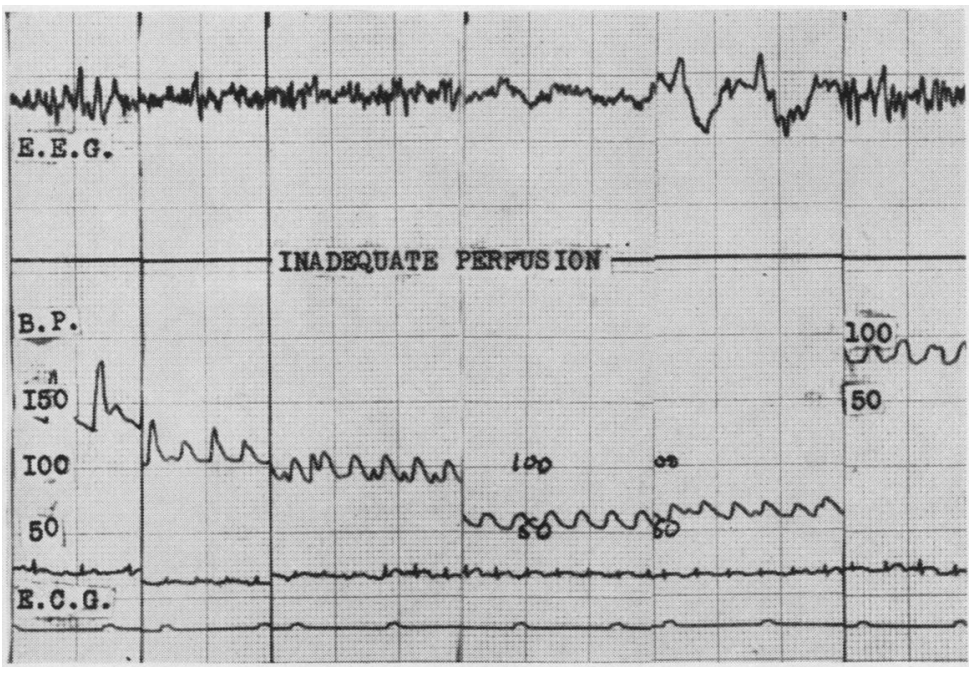

Fig. 4

was anaesthetized, and after thoracotomy the brachiocephalic and left brachial arteries were clamped for 20 minutes, depriving the brain of its blood supply from the carotid and vertebral arteries. As a result the E.E.G. tracing became almost flat after a period of marked slow wave pattern. This deterioration took about three minutes to develop. On release of the clamps, waves of medium frequency and greater than normal amplitude persisted for some time. However, after about 15 minutes a virtually normal E.E.G. was obtained (Fig. 2). This dog did not recover consciousness and there is little doubt that grave cerebral damage had been inflicted, but in spite of it the E.E.G. showed an apparent recovery. This illustrates the fallacy of regarding a return to normal of the E.E.G. after a period of cerebral anoxia as necessarily indicating recovery.
Perfusion with Desaturated Blood.-During perfusion of a dog, insufficient oxygen was supplied to the oxygenator, resulting in perfusion with dark blood with an oxygen saturation of $62 \%$. At this stage the E.E.G. became almost isoelectric. The oxygen supply was increased and the blood became red, with an oxygen saturation of $96 \%$, whereupon the E.E.G. resumed the normal pattern it had shown before perfusion was begun (Fig. 2b).

Normal Perfusion.-Fig. 3 shows an E.E.G. which we regard as indicating an adequate cerebral perfusion. Before perfusion the arterial blood pressure was $175 / 100 \mathrm{~mm}$. $\mathrm{Hg}$ and the E.E.G. was normal. During perfusion the blood pressure was maintained at $120 / 95 \mathrm{~mm}$. $\mathrm{Hg}$ and the electrical pattern remained unaltered. After perfusion the blood pressure regained its previous level, the 


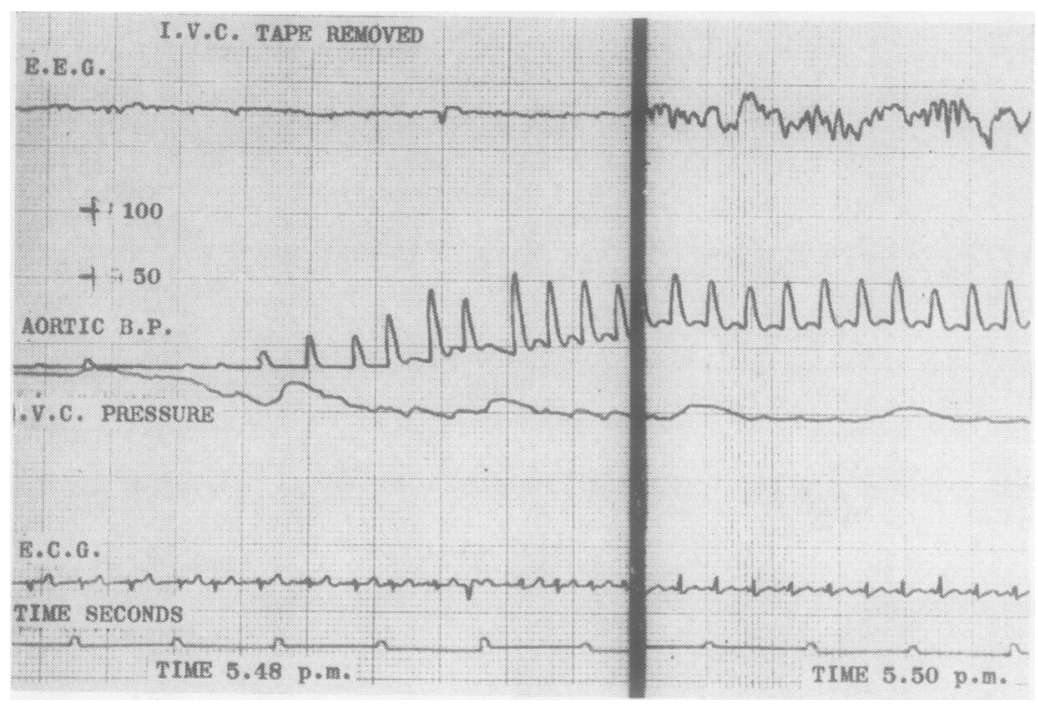

Fig. 5

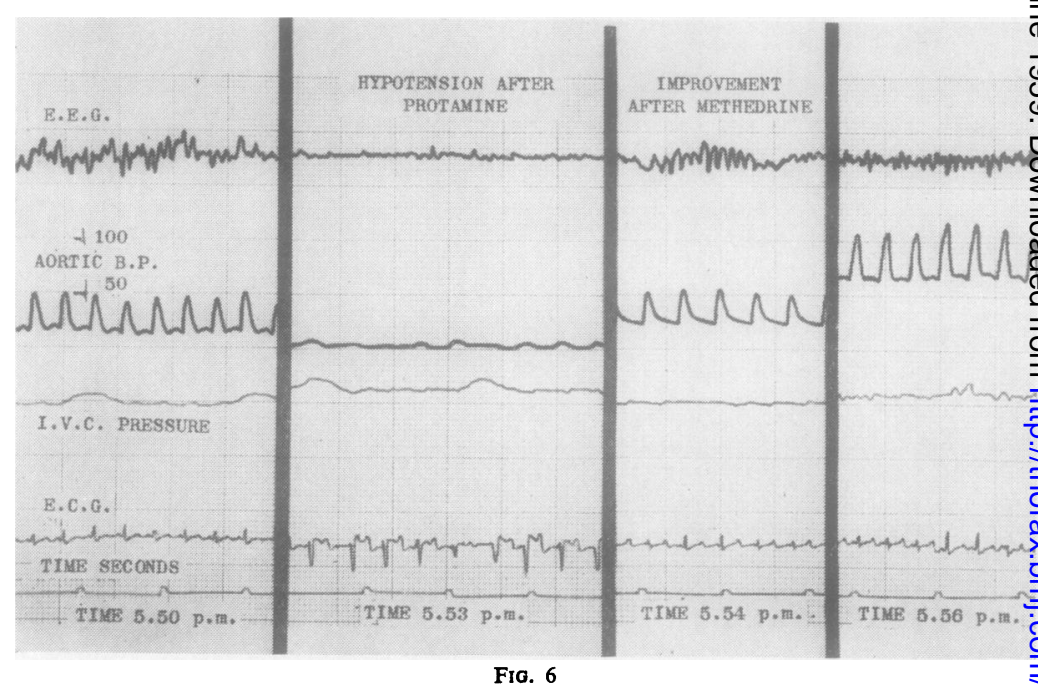

E.E.G. maintained a satisfactory pattern, and the animal made a normal recovery.

E.E.G. Associated With Hypotension.Marked hypotension from any cause will produce changes in the E.E.G. which are constant and reproducible.

Poor Perfusion.-The recording in Fig. 4 was obtained during a period of low blood pressure while perfusing a dog. Before perfusion the arterial pressure was $180 / 130 \mathrm{~mm}$. $\mathrm{Hg}$ and the E.E.G. pattern was normal. As perfusion proceeded the blood pressure fell to $140 / 105$ $\mathrm{mm}$. $\mathrm{Hg}$ and the trace remained unaltered. When the blood pressure fell to $65 / 50 \mathrm{~mm}$. Hg the amplitude decreased with a diminished frequency and slow waves supervened. When the blood pressure rose to $100 / 80 \mathrm{~mm}$. $\mathrm{Hg}$ the E.E.G. improved considerably.
Obstructed Venous Return.-Fig. 5 shows the effect of venous obstruction on the E.E.G. At the conclusion of a by-pass in a dog the blood pressure. fell to a very low level, the venous pressure rose considerably, and the E.E.G. became inactive $N$ The operator had failed to release the inferion vena caval tape completely, and when this waso corrected the arterial pressure rose, the venous pressure fell, and the E.E.G. pattern increased in amplitude and frequency.

Protamine Shock.-Fig. 6 is a record obtained following the accidental rapid administration of protamine sulphate intravenously at the end? of perfusion. The arterial pressure fell sharply? accompanied by a raised venous pressure. The E.C.G. complexes became markedly abnormal and the E.E.G. trace became inactive. Intravenous: methedrine was administered and the last segment 


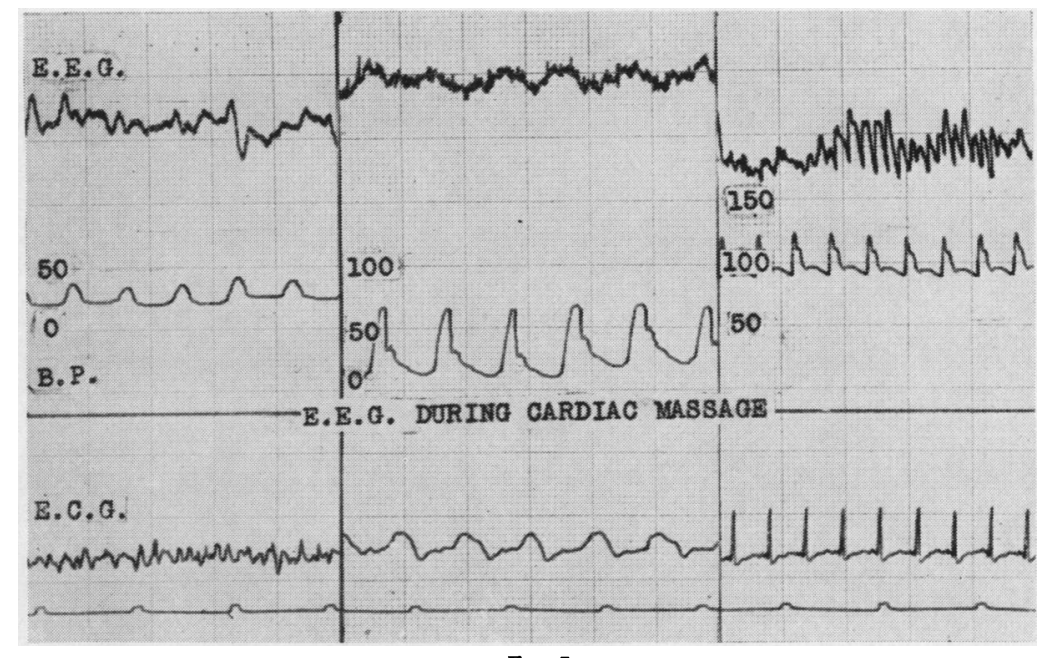

Fig. 7

\section{BRACHIAL PERFUS ION}

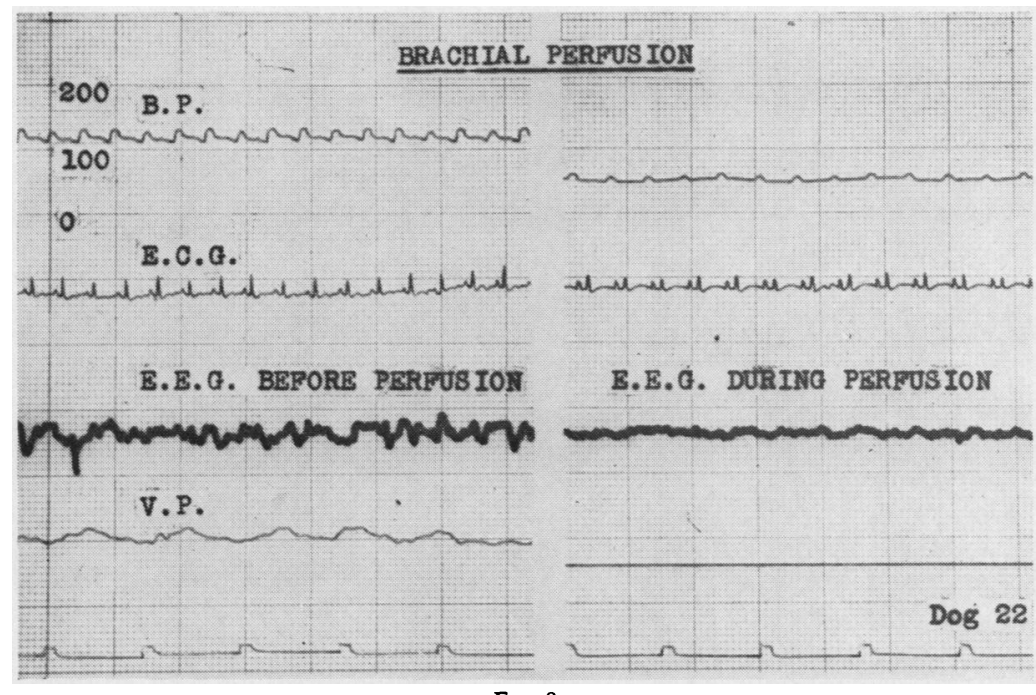

FIG. 8

of the trace shows its effect. The blood pressure rose to $120 / 60 \mathrm{~mm} . \mathrm{Hg}$ and the venous pressure fell. The E.C.G. complexes regained their normal appearance and the E.E.G. reverted to a normal pattern.

Inadequate Cardiac Massage.-Fig. 7 shows the response of the E.E.G. to inadequate and adequate cardiac massage. In a dog, following perfusion, ventricular fibrillation occurred as the last skin stitches were being inserted. The chest was opened again and cardiac massage begun. While the blood pressure remained at $30 / 20$ $\mathrm{mm}$. $\mathrm{Hg}$ the E.E.G. showed an increase in slow wave activity and this became normal only when more efficient massage produced a systolic blood pressure of $70 \mathrm{~mm}$. $\mathrm{Hg}$. This was adequate to allow successful electrical defibrillation.
EFfect on E.E.G. of Site of Cannulation WITH Low Flows.-There was an indication during our earlier experiments that the site of cannulation was of importance (Drew and others, 1957). In some experiments brachial artery cannulation was used with flow rates of 35 to $45 \mathrm{ml}$. per kg. body weight per minute. Fig. 8 shows the effect on the E.E.G. of such a perfusion at a rate of $45 \mathrm{ml}$. per $\mathrm{kg}$. The arterial pressure before perfusion was $120 / 100 \mathrm{~mm}$. $\mathrm{Hg}$ and the E.E.G. showed a normal pattern. With perfusion the blood pressure fell to $65 \mathrm{~mm}$. $\mathrm{Hg}$ systolic and the E.E.G. became of low frequency and amplitude. This dog died.

Fig. 9 shows the effect on the E.E.G. during perfusion of a dog with a similar flow but on this occasion via the carotid artery. Before 


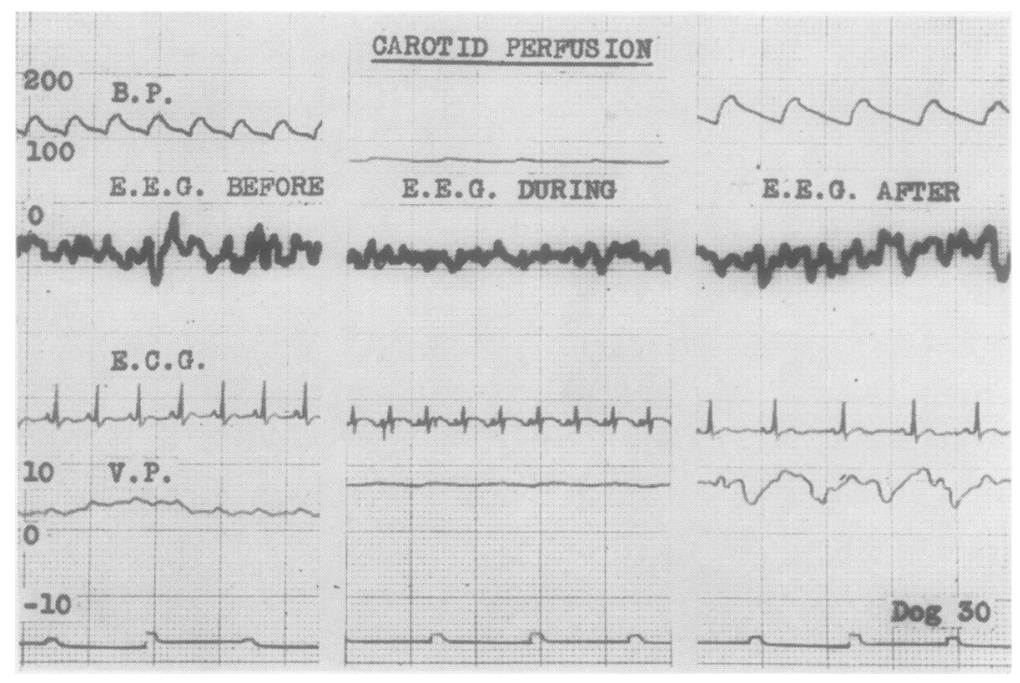

Fig. 9

perfusion the blood pressure was $130 / 100 \mathrm{~mm}$. $\mathrm{Hg}$ and the E.E.G. was within normal limits. During the by-pass the blood pressure fell to $65 \mathrm{~mm}$. $\mathrm{Hg}$ systolic as in the previous animal, but the E.E.G. did not change. This dog lived.

These observations suggest that at low flow rates perfusion of the carotid artery of the dog is more likely to produce an adequate cerebral blood flow than brachial perfusion, despite similar aortic blood pressures.

ThORACIC InLET ObSTRUCTION.-There is some doubt concerning the effect on the E.E.G. of acute superior vena caval obstruction. Fig. 10 was taken from records made during operation on an infant for closure of a ventricular septal defect. After transternal thoracotomy, but before perfusion, it was observed that the E.E.G. had assumed a slow wave pattern and had become inactive despite an apparently satisfactory circulation. The rib spreader was relaxed with rapid improvement in the E.E.G. pattern. It is believed that the poor E.E.G. was consequent on vascular obstruction at the thoracic inlet, but whether arterial or venous is speculative. Paneth, Sellers, Gott, Weirich, Allen, Read, and Lillehei (1957) found that congestion consequent on superior vena caval obstruction influenced the E.E.G. pattern unfavourably. However, Kirklin, McGoon, Patrick, and Theye (1958) reported that superior caval obstruction is not necessarily associated with E.E.G. changes, and quote a case of superior caval obstruction during clinical by-pass which was so severe that petechiae developed on the head and neck, but in which the E.E.G. remained unaltered.

Superior Vena Caval Obstruction.-Experiments not involving cardio-pulmonary by-pass were carried out to investigate further this

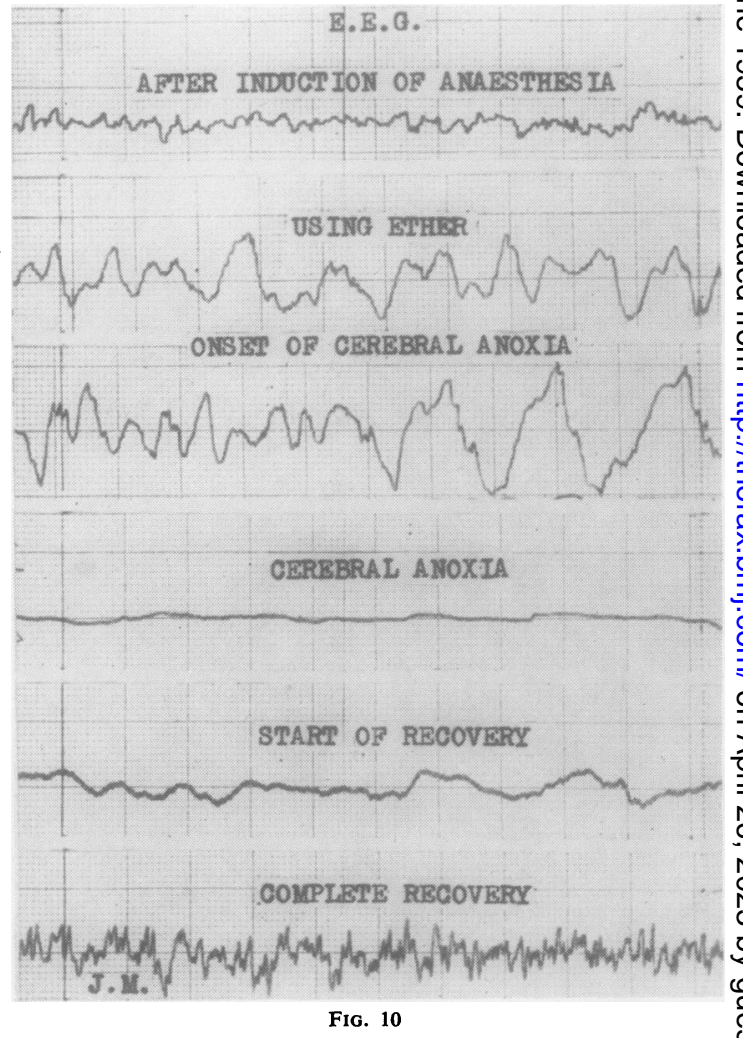

particular point. In the anaesthetized dog, the E.E.G. remains unaltered despite complete and prolonged deliberate obstruction of the superior vena cava. As is seen in Fig. 11, the superior vena caval pressure rose markedly and the arterial pressure fell slightly, but even after 30 minutes the E.E.G. remained unaltered.

It is of interest to observe the almost negligible effect of this manœuvre on the arterial pressure 


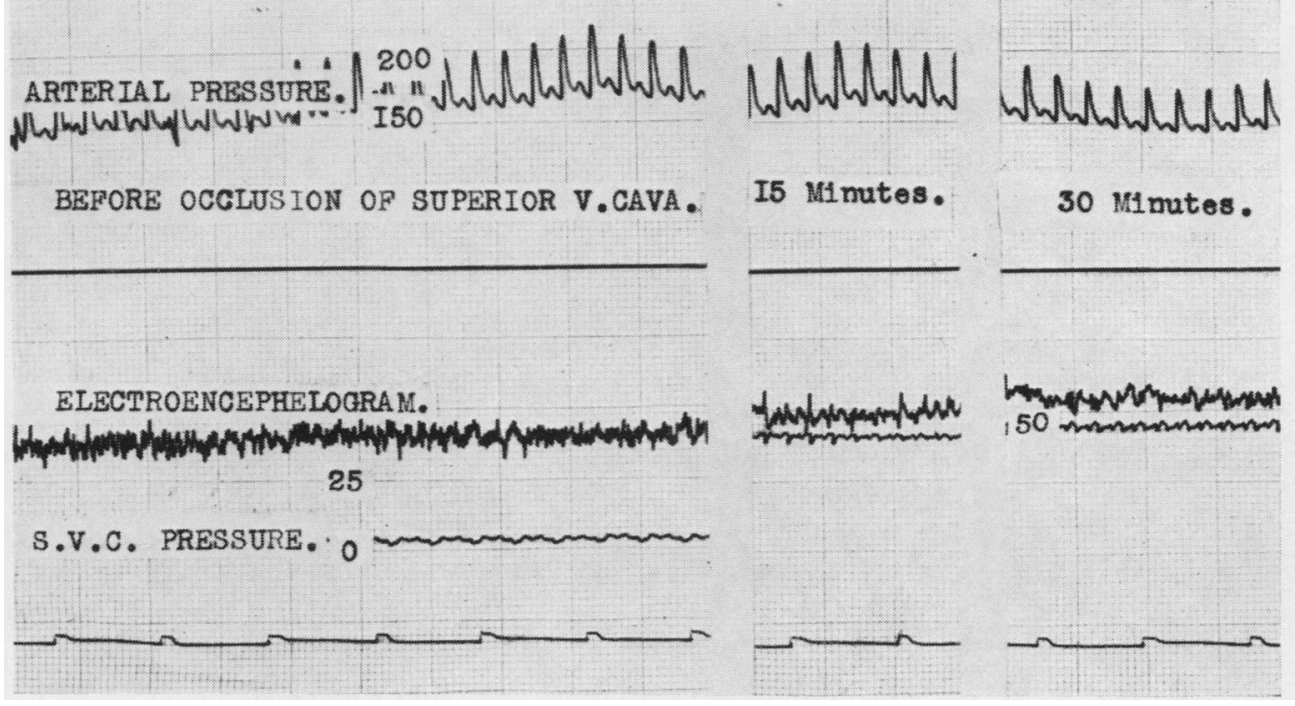

Fig. 11

in contrast to the marked fall in arterial pressure following inferior vena caval occlusion as in Fig. 5. The latter results in a greatly diminished venous return and a fall in cardiac output and this is reflected in the E.E.G. trace.

\section{Discussion and Conclusions}

This series of observations has been presented with the object of demonstrating the scope of E.E.G. recordings during alterations of cerebral blood flow, with special reference to the mechanical and surgical mishaps of cardiopulmonary by-pass.

While observations of the central arterial and venous blood pressures and the E.C.G. give important information, the E.E.G. provides the only convenient index of cerebral blood flow. Other workers arrive at similar conclusions. Thus, Theye, Patrick, and Kirklin (1957) reported the E.E.G. changes in patients undergoing cardiopulmonary by-pass and concluded that this instrument was a "useful monitoring device." Paneth and others (1957) discussed the routine use of the E.E.G. in clinical perfusion and considered that this afforded a "sensitive and valuable index of well-being." Scurr (1958), discussing the physiology of cardio-pulmonary by-pass, considered that "deterioration of the E.E.G. pattern under these conditions denoted a fall in cerebral blood flow below a safe level."

A method of grading the deterioration of the E.E.G. due to cerebral anoxia has been suggested by Hudson (1958). Any such grading, although arbitrary, has the merit of indicating minor changes and their degree. Should the E.E.G. pattern deteriorate during cardio-pulmonary by-pass, it is suggested that the following should be rapidly checked: (1) Arterial and venous pressures, (2) arterial and venous obstructions, (3) adequacy of oxygenation, (4) possible effect of drugs on the arterial pressure, and (5) possible obstruction at the thoracic inlet.

\section{SUMMARY}

A method of recording the E.E.G. during cardio-pulmonary by-pass is described.

The normal E.E.G. and several abnormal patterns obtained under different conditions are presented and described.

It is concluded that the E.E.G. is the most valuable monitor of cerebral blood flow during this type of surgery.

We wish to thank Dr. Peter Hansell, of the Department of Medical Photography, for reproducing the E.E.G. tracings.

\section{REFERENCES}

Drew, C. E., Cliffe, P., Scurr, C. F., Forrest, D. M., Pearce, D. J. King, P. A., Coles, H. M. T., Leveaux, V. M., and Zilva, J. F (1957). Brit. med. J., 2, 1323

DeWall, R. A., Warden, H. E., Read, R. C., Gott, V. L., Ziegler, N. R., Varco, R. L., and Lillehei, C. W. (1956). Surg. Clin. N. Amer., 36, 1025.

Hudson, W. A. (1958). Proc. roy. Soc. Med., 51, 591.

Kirklin, J. W., McGoon, D. C., Patrick, R. T., and Theye, R. A. (1958). In Extracorporeal Circulation, ed. J. G. Allen, p. 131 Thomas, Springfield, Illinois.

Paneth, M., Sellers, R., Gott, V. L., Weirich, W. L., Allen, P., Read, R. C., and Lillehei, C. W. (1957). J. thorac. Surg., 34, 570.

Scurr, C. F. (1958). Proc. roy. Soc. Med., 51, 581.

Theye, R. A., Patrick, R. T., and Kirklin, J. W. (1957). J. thorac. Surg., 34, 709 . 